\title{
Experiências de Ensino da Computação Desplugada em Diferentes Séries da Educação Fundamental Maior
}

\author{
Alberto Alan Raiol ${ }^{1}$, Ana Carina Lima ${ }^{1}$, Breno Sousa ${ }^{1}$, João Sarges ${ }^{1}$, \\ Rafael Santos $^{1}$, Fábio Bezerra ${ }^{1}$ \\ ${ }^{1}$ Instituto Ciberespacial - Universidade Federal Rural da Amazônia \\ Avenida Presidente Tancredo Neves, 2501 - Belém-Pará \\ fabio.bezerra@ufra.edu.br
}

\begin{abstract}
Resumo. O estudo da computação é visto como algo complexo e que possui conceitos de difícil abstração. Esta leitura da área da computação poderia ser melhorada se os alunos da educação básica, do ensino fundamental ou médio, tiverem o contato com a computação como uma ciência. No entanto, em que momento do ciclo de formação a computação poderia ser apresentada a esse alunado da educação básica? Com a intenção de mostrar a importância da computação e facilitar o ensino e o aprendizado desta área, o presente trabalho relata a aplicação da Computação Desplugada como método de ensino bem aceito pelos estudantes do ensino fundamental maior. Os resultados dessa experiência apontam que o sétimo ano foi a série que melhor respondeu bem ao conteúdo trabalhado em sala de aula.
\end{abstract}

\begin{abstract}
The study of computing is seen as complex and of hard abstraction. This understanding of computing area could be improved if the students of basic education, elementary or high school, had contact with computing as a science. However, when in the training cycle computing science could be presented to these students of basic education? In order to show the importance of computing science and to facilitate the teaching and the learning of this area, this paper describes the application of computing science unplugged with students of upper elementary education. The results of this experiment indicate that the seventh year was the moment that best responded to the content worked in the classroom.
\end{abstract}

\section{Introdução}

O ano de 1998 teve como destaque o fim da primeira etapa do processo da informatização das escolas públicas brasileiras. A partir de então, há uma preocupação sobre a forma adequada de se aplicar a computação nas escolas, para que o ensino de conceitos computacionais nas mesmas possa caminhar de forma legítima ao que a disciplina oferece [BORGES NETO 1999]. Passada esta fase de primeiro contato com a informatização das escolas, observa-se que atualmente no Brasil as práticas de ensino de conceitos da Computação nas escolas não proporcionam o conhecimento necessário afim de que os alunos avancem para um futuro promissor nessa área, especialmente porque a computação ainda não é um elemento curricular obrigatório. No ambiente escolar pouco se observa o ensino da computação enquanto ciência, uma vez que os alunos realizam atividades mais práticas envolvendo hardwares e softwares específicos, talvez porque ainda se acredita que a computação resume-se à habilidade de manusear e configurar equipamentos e 
programas de computador, podendo também difundir o pensamento incorreto que os computadores são autossuficientes e solucionadores de qualquer problema, não necessitando da intervenção humana para funcionar [da Conceição Araújo et al. 2015].

Acreditamos que um grande ponto que dificulta a inserção de fundamentos computacionais na educação básica é o fato do tema não fazer parte da diretriz curricular brasileira, fazendo com que as crianças convivam quando possível, com a mera utilização dos recursos básicos da máquina, sem exploração da interdisciplinaridade existente entre as outras disciplinas e amadurecimento de habilidades estimulados pela ciência da computação, como raciocínio lógico e o pensamento computacional [Costa et al. 2012]. Muitos trabalhos discutem a necessidade de a Computação ser trabalhada como ciência desde o ensino básico [França et al. 2012, Bell et al. 2011, da Siva et al. 2015, de França and do Amaral 2013]. Neste contexto, a Sociedade Brasileira de Computação (SBC) apresenta-se como um importante instrumento, pois promove anualmente eventos para buscar debates em diferentes temas relacionados ao ensino de Computação no país.

Neste cenário de inserção da computação como ciência na educação, a computação desplugada apresenta-se como um importante método de ensino. O material que foi desenvolvido por três professores de Ciência da Computação - Tim Bell, Lan H. Witten e Mike Fellows - e disponível gratuitamente no livro "Computer Science Unplugged", com tradução para o português, destaca-se como uma alternativa eficaz na finalidade de atenuar os desafios encontrados para o ensino dos conceitos de computação nas escolas. Conforme [Bell et al. 2011], sem o uso do computador e de forma descontraída, a Computação Desplugada pode ser empregada em uma sala de aula normal e fundamentos importantes da computação podem ser ensinados de forma fácil aos alunos. Por isso, as atividades da computação desplugada estão sendo utilizadas por educadores e não especialistas em computação em diversos países do mundo, tanto dentro quanto fora dos ambientes escolares. No caso das escolas públicas brasileiras, o método da computação desplugada torna-se especialmente importante, pois democratiza o acesso a um importante conteúdo da ciência sem precisar investir em um laboratório de ensino especializado.

Este artigo tem como objetivo relatar a experiência que os autores vivenciaram com quatro turmas do ensino fundamental maior (sexto, sétimo, oitavo e nono ano) de uma instituição pública de ensino em Belém, utilizando o método da computação desplugada. O objetivo dessa experiência na escola era aproximar os estudantes de conteúdos da ciência da computação, fomentar a afinidade pela ciência da computação, mas principalmente, avaliar qual ano/série melhor responderia, quanto a aprendizagem e motivação, aos conteúdos apresentados.

Este trabalho está organizado da seguinte forma: na Seção 2, descrevemos os materiais e métodos utilizados e o público que participou de nossas experiências; na Seção 3, apresentamos as lições aprendidas com as intervenções; na Seção 4, apresentamos as experiências de trabalhos com ações semelhantes as relatadas aqui; por fim, na Seção 5, apresentamos as nossas considerações finais e propostas para trabalhos futuros. 


\section{Materiais e Métodos}

Nesta seção abordaremos o método de ensino aplicado em nossas intervenções (Seção 2.1) e apresentaremos o planejamento das oficinas, o público participante (Seção 2.2) e processo de ensino nas aulas (Seção 2.3).

\subsection{Método de Ensino: Computação Desplugada}

A computação desplugada é uma técnica que tem como objetivo ensinar os fundamentos da computação para estudantes e pessoas de diferentes idades, apresentando com uma linguagem simples como os computadores funcionam, porém sem utilizar o computador como instrumento de ensino [Bell et al. 2009]. Assim, as atividades podem ser aplicadas em qualquer escola, justamente por não necessitar de equipamentos eletrônicos, ocasionando a desvinculação da ideia do aprendizado de computação que é popularmente atrelada à utilização de um computador.

O livro "Computação Desplugada"foi criado por Tim Bell, Ian H. Witten e Mike Fellows. Possui 12 ricas atividades que cobrem diferentes áreas ou temas da computação, e pode ser baixado gratuitamente em www.csunplugged.org. O livro está organizado em três partes: dados (cinco atividades), algoritmos (cinco atividades) e linguagens (duas atividades).

Este trabalho limitou-se a primeira parte do livro, que é fundamental para entender como os computadores representam, armazenam e trocam dados. Cada uma das 12 atividades geralmente possui cinco estruturas: atividades (sumário, matérias correlacionadas, habilidades, idades e material), conteúdo (introdução e discussão), folha de atividade (instruções, discussão e atividades), uma explicação final e mais aprofundada do conteúdo, e resoluções e dicas de aprimoramento da atividade.

\subsection{Ambiente e Escopo da Experiência: Escola, Turmas e Atividades}

As experiências expostas neste trabalho foram realizadas com alunos do ensino fundamental maior, entre os meses de novembro de 2014 e fevereiro de 2015 na Escola Estadual de Ensino Fundamental e Médio Barão de Igarapé Miri, localizada na periferia de Belém.

Tiveram acesso às atividades com a computação desplugada apenas uma turma de cada uma das séries, do sexto ao nono ano. Essa limitação - apenas uma turma de cada série e apenas três atividades - está relacionada à disponibilidade de horário, no mesmo turno das aulas, que a escola poderia ceder a execução das oficinas. No entanto, mesmo considerando que apenas quatro turmas foram atendidas, ao final da oficina, 110 alunos tiveram contato com os conteúdos planejados para a ação. No caso, apresentamos as três primeiras atividades, das 12 disponíveis no livro: "Números Binários", "Representação de Imagens"e "Compressão de Texto".

Cada atividade do livro foi planejada em formato de oficina, compreendendo aproximadamente a duração de 90 minutos. As oficinas eram realizadas duas vezes na semana na escola, nos dias de quarta e sexta-feira, sendo que no primeiro momento da semana, a oficina era aplicada para as turmas de sexto e nono ano, e no segundo momento, a oficina era realizada com os alunos das turmas de sétimo e oitavo ano (ver Tabela 1).

Com um público dividido em quatro séries escolares, as oficinas contemplaram alunos com idades que variaram entre onze a quatorze anos. Todavia, o planejamento 
Tabela 1. Quantidade de Participantes por Turma

\begin{tabular}{l|r}
\hline Turmas & Numero de Participantes \\
\hline Sexto ano & 31 \\
\hline Sétimo ano & 30 \\
\hline Oitavo ano & 25 \\
\hline Nono ano & 24 \\
\hline Total & 110 \\
\hline
\end{tabular}

das aulas, bem como sua execução, se fez de forma semelhante para todas as quatro turmas. Entretanto, vale ressaltar que apesar de termos planejado e agendado antecipadamente as aulas, junto à direção da escola e aos professores, que cederam alguns de seus horários, houveram alterações constantes na agenda planejada, motivadas tanto por parte dos mesmos docentes que em período de avaliações acabaram utilizando os horários que em outrora haviam cedido, quanto por programações da Secretaria Estadual de Educação e eventos da própria instituição. Na Tabela 2 apresentamos os conteúdos trabalhados, os materiais utilizados e os objetivos de cada aula.

\section{Tabela 2. Planejamento Resumido da Oficina}

\begin{tabular}{|c|c|c|c|}
\hline Aula & Conteúdo & Materiais & Objetivo \\
\hline $1^{\circ} \mathrm{Dia}$ & $\begin{array}{l}\text { Atividade } \text { I } \\
\text { Números Binários } \\
\text { - Conversão de } \\
\text { decimal para } \\
\text { binário, binário } \\
\text { para decimal; de- } \\
\text { safio do código, } \\
\text { decodificação e } \\
\text { envio de mensagem. }\end{array}$ & $\begin{array}{l}6 \text { cartões de tama- } \\
\text { nho A4, crachás para } \\
\text { identificação dos gru- } \\
\text { pos, lápis, borracha, } \\
\text { marcadores, palito de } \\
\text { churrasco, rolo de fita } \\
\text { crepe, folha de isopor e } \\
\text { percevejos. }\end{array}$ & $\begin{array}{l}\text { Compreender o sistema } \\
\text { binário, realizando a con- } \\
\text { versão de valores decimais } \\
\text { em binários e binários em } \\
\text { decimais. }\end{array}$ \\
\hline $2^{\circ} \mathrm{Dia}$ & $\begin{array}{l}\text { Atividade II - } \\
\text { Representação } \\
\text { de Imagens - } \\
\text { Codificando e Deco- } \\
\text { dificando imagens } \\
\text { (formas geométricas } \\
\text { e letras do alfabeto). }\end{array}$ & $\begin{array}{l}40 \text { cartões } 5 * 5 \mathrm{~m} \text {, iso- } \\
\text { por, fita crepe, perceve- } \\
\text { jos, borracha e lápis. }\end{array}$ & $\begin{array}{l}\text { Conhecer e entender como } \\
\text { os computadores represen- } \\
\text { tam as imagens, identifi- } \\
\text { cando as diferentes quanti- } \\
\text { dades de pixels das figuras. }\end{array}$ \\
\hline $3^{\circ} \mathrm{Dia}$ & $\begin{array}{l}\text { Atividade III - Com- } \\
\text { pressão de Texto - } \\
\text { Identificando mode- } \\
\text { los de vocábulos e } \\
\text { frases. }\end{array}$ & $\begin{array}{l}\text { Textos (poemas e canti- } \\
\text { gas), lápis, caneta, bor- } \\
\text { racha. }\end{array}$ & $\begin{array}{l}\text { Compreender a forma efi- } \\
\text { ciente do computador sal- } \\
\text { var as informações, com a } \\
\text { reutilização de dados, fa- } \\
\text { zendo a supressão de duas } \\
\text { ou mais palavras na com- } \\
\text { pressão de textos. }\end{array}$ \\
\hline
\end{tabular}

Adaptamos as atividades para serem aplicadas em formato de competição entre equipes, havendo a formação de pequenos grupos de alunos, que interagiam entre si para solucionarem os desafios propostos nas aulas. Dessa forma, as competições foram organizadas visando criar uma atmosfera de aprendizagem divertida[Scaico et al. 2012]. 


\subsection{Dinâmica das Aulas}

O envolvimento dos estudantes com as atividades aconteceram de seguinte maneira: inicialmente uma explicação do conteúdo de forma expositiva e com demonstrações; em seguida um exercício individual para aproximar o aluno do conteúdo; finalmente, foram realizadas dinâmicas competitivas entre os grupos para fixação dos conteúdos abordados. A dinâmica em grupo previa uma premiação simbólica, então o grupo que executasse a tarefa em menor tempo ganhava um brinde a mais.

Semelhante ao trabalho apresentado em [Bezerra 2014], para aproximar os alunos do vocabulário ligado às tecnologias e ajudar na coordenação das dinâmicas em sala, criamos crachás para identificar os grupos, cujos nomes estavam associados: às linguagens de programação Python, Ruby, Java e Php; aos provedores de e-mail Yahoo, Gmail e Hotmail; às redes sociais Twitter, WhatsApp, Facebook e Instagram. Para nossa surpresa, mesmo considerando o contexto social, econômico e geográfico dos alunos, com exceção das linguagens de programação, tanto os provedores quanto as redes sociais já eram expressões familiares aos mesmos.

Durante as duas tarefas iniciais, as avaliações das apresentações pelos estudantes ocorreram com base em dois conceitos, S (Sim) para indicar que o aluno entendeu ou assimilou as atividades lúdicas trabalhadas e $\mathrm{N}$ (Não) para indicar que não entendeu. $\mathrm{Na}$ terceira tarefa foi acrescentada a resposta $\mathrm{R}$ (Regular) à avaliação, a fim de aumentar a precisão da opinião do aluno quanto a aprendizagem e motivação do conteúdo.

\section{Resultados e Discussões}

Os resultados produzidos pela experiência estão relacionados às seguintes observações: resposta a aprendizagem do conteúdo trabalhado e motivação dos alunos na participação das atividades. A aprendizagem foi um item coletado por dois métodos: (i) auto-avaliação dos alunos, que respondiam em formulário próprio se conseguiram ou não absorver o conteúdo apresentado; (ii) observação dos instrutores durante as gincanas. Enquanto a motivação foi um item medido através da frequência dos alunos às atividades.

\subsection{Aprendizagem do Conteúdo}

Ao final de cada oficina os alunos respondiam em formulário próprio se haviam entendido o conteúdo da atividade apresentada. Com respostas simples, representadas por "Sim"ou "Não"os alunos responderam esse questionamento. Para a última atividade a alternativa "Regular" foi adicionada ao formulário, para indicar que o aluno entendeu o conteúdo de forma incompleta ou não sente domínio do mesmo.

Apresentamos na Tabela 3, as respostas dos alunos presentes em cada dia de atividade, para cada turma, o percentual de respostas positivas e negativas. Nessa tabela podemos observar que todos as turmas envolvidas responderam bem à aprendizagem de todos os conteúdos apresentados. Com exceção da atividade de "Representação de Imagens", para a turma do sexto ano, que respondeu positivamente para 78,3\% dos alunos presentes. No entanto, não chega a ser um índice ruim.

$\mathrm{Na}$ observação dos instrutores, os alunos da turma do sétimo se desenvolveram melhor na resoluções das atividades, pois apresentaram-se mais articulados, desenvoltos e participativos nas aulas. Em outro contexto, notamos que os alunos da turma do sexto 
Tabela 3. Respostas da auto-avaliação por cada atividade

\begin{tabular}{l|c|c|c|c|c|c|c|c|c|c|c|c|c|c}
\hline & \multicolumn{4}{|c|}{ Atividade 1 } & \multicolumn{4}{c|}{ Atividade II } & \multicolumn{5}{c}{ Atividade III } \\
\hline Turmas & Sim & $\%$ & Não & $\%$ & Sim & $\%$ & Não & $\%$ & Sim & $\%$ & Não & $\%$ & Regular & $\%$ \\
\hline Sexto ano & 18 & 81,8 & 4 & 18,2 & 18 & 78,3 & 5 & 21,7 & 11 & 100 & 0 & 0 & 0 & 0 \\
\hline Sétimo ano & 18 & 90 & 2 & 10 & 22 & 100 & 0 & 0 & 16 & 100 & 0 & 0 & 0 & 0 \\
\hline Oitavo ano & 18 & 90 & 2 & 10 & 19 & 100 & 0 & 0 & 6 & 100 & 0 & 0 & 0 & 0 \\
\hline Nono ano & 17 & 100 & 0 & 0 & 11 & 100 & 0 & 0 & 10 & 83,3 & 0 & 0 & 2 & 16,7 \\
\hline
\end{tabular}

ano tiveram mais dificuldades em compreender algumas atividades propostas, recorrendo muitas vezes a ajuda dos monitores, para sanar as dúvidas e realizar as tarefas.

As turmas do oitavo e nono ano também apresentaram um bom desempenho na realização das tarefas, contudo, em ambas as turmas percebemos uma certa desmotivação de alguns alunos na evolução das aulas, sobretudo na primeira e segunda atividade - ex.: relatos de falta de interesse para realizar a tarefa. Assim no decorrer das aulas, apenas os alunos motivados foram os mais presentes e participativos.

Tabela 4. Respostas da auto-avaliação de todo o conteúdo

\begin{tabular}{l|c|l|c|l|c|l}
\hline & \multicolumn{2}{|c|}{ Sim } & \multicolumn{2}{c|}{ Não } & \multicolumn{2}{c}{ Regular } \\
\hline Turmas & Respostas & $\%$ & Respostas & $\%$ & Respostas & $\%$ \\
\hline Sexto ano & 47 & 83,93 & 9 & 16,07 & 0 & 0 \\
\hline Sétimo ano & 56 & 96,55 & 2 & 3,45 & 0 & 0 \\
\hline Oitavo ano & 43 & 95,55 & 2 & 4,45 & 0 & 0 \\
\hline Nono ano & 38 & 95 & 0 & 0 & 2 & 5 \\
\hline
\end{tabular}

$\mathrm{Na}$ Tabela 4, encontram-se as respostas dos alunos por turma sobre o que foi questionado somando-se os três dias de atividades. Nesse contexto, nota-se que em todas as turmas o percentual de respostas positivas (Sim) dos alunos é bem significativa, visto que a turma do sexto ano apresentou 83,93\% de confirmação de entendimento do conteúdo pelos alunos, a turma do sétimo ano $96,55 \%$, a do oitavo ano $95,55 \%$ e nono ano $95 \%$.

\subsection{Motivação das turmas}

Entendemos que a motivação é uma aspecto humano e pessoal, portanto, é algo individual de cada aluno das turmas que essa experiência relata. No entanto, para o contexto da avaliação dessa experiência, aplicaremos o significado de motivação para a turma, ou conjunto de alunos, de forma claramente simplificada. No caso, o aspecto da motivação da turma relatado neste trabalho refere-se à frequência da turma em cada uma das atividades, ou seja, $70 \%$ de frequência significa que $70 \%$ dos alunos estiveram presentes na aula.

Apesar do conteúdo das oficinas ser extra-curricular, observamos uma participação razóavel dos alunos às oficinas. Acreditamos que esse interesse ao longo das três atividades esteve ligado as novas práticas de ensino proporcionada pelo método das aulas de computação desplugada, uma vez que as mesmas são desenhadas para promover a interação e curiosidade dos apresendizes. A Tabela 5 ilustra a frequência das turmas, das quais a do sétimo ano ganha destaque por apresentar maior frequência às aulas.

\subsection{Discussões}

Os resultados relatados nessa experiência corroboram com os relatos de outros trabalhos da literatura, que apontam a riqueza e vantagens da aplicação do método da computação 
Tabela 5. Frequências das turmas nas oficinas

\begin{tabular}{l|r}
\hline Turmas & Frequência da turma (\%) \\
\hline Sexto ano & 60,22 \\
\hline Sétimo ano & $\mathbf{6 4 , 4 4}$ \\
\hline Oitavo ano & 60 \\
\hline Nono ano & 55,55 \\
\hline
\end{tabular}

desplugada na educação básica.

Especificamente nessa experiência, acreditamos que a computação desplugada apresentou-se mais apropriada aos alunos do sétimo ano, enquanto que a turma do sexto ano teve maior percentual de rejeição. Contudo, acreditamos que o método apresenta-se como uma alternativa viável para qualquer série do ensino fundamental maior, especialmente quando consideramos que a rejeição foi, de uma forma geral, pequena.

\section{Trabalhos Relacionados}

Alguns autores ultimamente vêm discutindo a importância da inclusão da ciência da computação no currículo da educação básica [de França and do Amaral 2013, de Souza Barbosa et al. 2015, da Siva et al. 2015]. Diversos países desenvolvidos já apresentam um currículo mínimo para o ensino de computação na educação básica. No Brasil, diversas práticas vem sendo aplicadas para alunos do ensino fundamental e médio, trazendo contribuições através de estudos de métodos que podem futuramente ser incluídos no currículo de computação para a educação básica, tais práticas estão relatadas nos trabalhos de [de Paiva et al. 2015, Scaico et al. 2011, de França et al. 2013, Andrade et al. 2013, Scaico et al. 2012]. Em [de França and do Amaral 2013] os autores realizaram um mapeamento sistemático da produção cientifica brasileira nos anos de 2009 à 2012, com o objetivo de verificar quais práticas podem ser adotadas no país. Nesse mapeamento os autores notaram que a computação desplugada ganhou destaque nos anos de 2011 e 2012.

Em [de Souza Barbosa et al. 2015] os autores apresentam diversos métodos utilizados no ensino de computação na educação básica. No caso, a computação desplugada vem ganhando destaque nas pesquisas, porém ainda há poucos resultados sobre a avaliação e estratégias de resolução das atividades desplugadas que estão sendo desenvolvidas. Em [de Souza Barbosa et al. 2015] foi realizado o planejamento, execução e identificação das estratégias desenvolvidas pelos alunos do primeiro ano do ensino médio, em uma gincana desplugada. Mesmo com algumas dificuldades, os estudantes conseguiram desenvolver as técnicas propostas pelos monitores e também utilizaram técnicas próprias para a resolução das atividades.

As conexões interdisciplinares da ciência da computação são colocadas em evidência em [de Paiva et al. 2015]. No caso, os autores relatam a aplicação interdisciplinar da computação com sete disciplinas regulares da educação básica. Em [Scaico et al. 2011], através do projeto "Sem matemática não existe computação", os autores também reforçam o papel interdisciplinar da computação.

Em [da Siva et al. 2015] relatam uma experiência com alunos do nono ano da ensino fundamental maior, baseada no Model Curriculum for k12 Computer Sci- 
ence $^{1}$ e nas atividades do livro Computer Science Unplugged. Os trabalhos de [de França et al. 2013, Andrade et al. 2013, Scaico et al. 2012] relatam experiências semelhantes com a computação desplugada, a fim de disseminar a computação na educação básica e desenvolver o pensamento computacional.

No contexto de programação de computadores, em [de França et al. 2013] os autores realizaram um projeto de programação com Scratch. No caso, as atividades foram desenvolvidas abordando alguns trabalhos realizados na escola nos anos de 2010 a 2012, envolvendo a programação de computadores de forma lúdica, desenvolvimento do raciocínio lógico e o ensino de conceitos computacionais.

Em [Andrade et al. 2013] os autores relatam uma proposta metodológica para desenvolver o Computational Thinking Toolkit. Para isso, foram realizadas atividades lúdicas para estudantes do ensino fundamental, envolvendo conceitos básicos da computação. Em [Scaico et al. 2012] os autores combinam o uso da computação desplugada e do ensino de programação com scratch, para que os alunos do ensino médio possam desenvolver habilidades e competências com a área da computação, bem como aumentar o interesse pela área.

\section{Considerações Finais e Trabalhos Futuros}

Neste trabalho levamos a uma escola pública de Belém o ensino da ciência da computação, o que causou bastante entusiasmo nos alunos, pois responderam positivamente as expectativas. Além disso, pudemos observar que em todas as turmas investigadas, as respostas dos alunos quanto à compreensão dos conteúdos abordados, foi bastante expressiva, dando indícios que a aprendizagem dos conceitos trabalhados foram alcançados. Nesse cenário, em ênfase, a turma do sétimo ano (antiga sexta série) apresentou os melhores resultados, ficando também acima das demais em assiduidade nas aulas e na avaliação dos monitores, sendo a turma que teve maior aceitação e entendimento dos conteúdos ensinados nas aulas. Portanto, uma hipótese que pode ser melhor investigada é se o sétimo ano do ensino fundamental é o momento mais favorável para aplicação do método da computação desplugada.

Mais do que isso, este trabalho relata a experiência docente dos autores com estudantes de diferentes séries do ensino fundamental maior. Aos autores ainda em formação, houve claramente um amadurecimento acadêmico e pedagógico, pois permitiu o exercício prático das teorias apresentadas na universidade, a experiência docente através do contato professor-aluno, e a vivência do contexto escolar com todas as suas peculiaridades. Para os alunos, notamos o entusiasmo com "o novo", pois a ciência da computação foi apresentada como um conteúdo interessante e útil, que os alunos não têm naturalmente acesso, uma vez que não faz parte do currículo da educação básica. Um terceiro ente beneficiado com as ações relatadas neste artigo foi a escola, pois foi uma oportunidade para dialogar e repensar as ações que melhoram o processo de ensino e aprendizagem entre a escola, os alunos e os bolsistas.

Acreditamos que o contato com a computação, desde cedo, pode ser um estimulante para que esses alunos optem pela computação como carreira profissional. Assim, re-

\footnotetext{
${ }^{1}$ Modelo proposto pela Association for Computing Machinery (ACM), que serve como base e fornece orientações sobre as práticas de ensino de computação em diferentes etapas da educação [Tucker et al. 2003]
} 
alizar a mesma experiência com alunos do último ano do ensino médio pode ajudar a identificar o quanto com contato com esses conteúdos influenciam na escolha da computação como atividade profissional. Outro objetivo futuro é aprimorar o método de ensino e os materiais e atividades utilizadas nas oficinas, a fim de melhorar a compreensão dos fundamentos da ciência da computação pelos educandos por meio da Computação Desplugada.

Ainda como trabalhos futuros, pretendemos explorar todos os conteúdos presentes no livro de [Bell et al. 2011], bem como aplicar nossas intervenções nas demais séries do ensino fundamental menor, não contempladas neste trabalho. Outro fator a ser explorado seria verificar se as atividades trabalhadas no livro, poderiam ajudar os alunos em conteúdos relacionados a matemática, já que algumas atividades colocam em prática alguns conteúdos como a soma, a exponenciação, os símbolos matemáticos, dentre outros.

\section{Agradecimentos}

Os autores agradecem o programa PIBID-UFRA, que financiou a realização deste trabalho através das bolsas de iniciação à docência.

\section{Referências}

Andrade, D., Carvalho, T., Silveira, J., Cavalheiro, S., Foss, L., Fleischmann, A. M., Aguiar, M., and Reiser, R. (2013). Proposta de atividades para o desenvolvimento do pensamento computacional no ensino fundamental. In Anais do Workshop de Informática na Escola, volume 1, page 169.

Bell, T., Witten, I. H., and Fellows, M. (2011). Computer science unplugged. ensinando ciência da computação sem o uso do computador. Tradução por: Luciano Porto Barreto. Disponível em: http://csunplugged. org/books. Acesso: Março de.

Bezerra, F. (2014). Bem mais que os bits da computação desplugada. In Anais do Worksop de Informática na Educação 2014, Dourados, MS.

BORGES NETO, H. (1999). Uma classificação sobre a utilização do computador pela escola. Revista Educação em Debate, ano, 21:135-138.

Costa, T., Batista, A., Maia, M., Almeida, L., and Farias, A. (2012). Trabalhando fundamentos de computação no nível fundamental: experiência de licenciandos em computação da universidade federal da paraíba. In XX Workshop de Educação em Computação-WEI. Curitiba, PR, Brasil.

da Conceição Araújo, D., Rodrigues, A. N., de Araújo Silva, C. V., and Soares, L. S. (2015). O ensino de computação na educação básica apoiado por problemas: Práticas de licenciandos em computação. XXIII do WEI - Workshop sobre Educação em Computação.

da Siva, S. F., Barbosa12, A. F., de Souza12, A. A., Lauyse, E. G. d. S. M., and Rogério, S. d. O. S. (2015). Relato de experiência de ensino de computação no ensino fundamental em estágio supervisionado da universidade de pernambuco no campus garanhuns. In XXI Workshop sobre Educaç ao em Computaç ao.

de França, R. S., da Silva, W. C., and do Amaral, H. J. C. (2013). Despertando o interesse pela ciência da computação: Práticas na educação básica. In Proceedings of International Conference on Engineering and Computer Education, volume 8, pages 282-286. 
de França, R. S. and do Amaral, H. J. C. (2013). Ensino de computação na educação básica no brasil: Um mapeamento sistemático. In XXI Workshop sobre Educaç ao em Computaç ao.

de Paiva, L. F., Ferreira, A. C., Rocha, C., Barreto, J., Melhor, A., Lopes, R., and Matos, E. (2015). Uma experiência piloto de integração curricular do raciocínio computacional na educação básica. In Anais dos Workshops do Congresso Brasileiro de Informática na Educação, volume 4, page 1300.

de Souza Barbosa, A. V., Neto, A. F. P., de Oliveira, R. N. R., da Costa, T. L. S., Souto, A. L., De Araújo, O., and Costa, F. V. S. (2015). O ensino de conceitos computacionais para alunos do ensino médio: relato de experiência de uma gincana e das estratégias utilizadas pelos alunos na resolução das atividades desplugadas. In XXI Workshop sobre Educaç ao em Computaç ao.

França, R. d., Silva, W. d., and Amaral, H. d. (2012). Ensino de ciência da computaçao na educaçao básica: Experiências, desafios e possibilidades. In XX Workshop sobre Educação em Computação.

Scaico, P. D., Corlett, E. F., Paiva, L. F., Raposo, E. H. S., and Alencar, Y. (2012). Relato da utilização de uma metodologia de trabalho para o ensino de ciência da computação no ensino médio. In Anais do Workshop de Informática na Escola, volume 1.

Scaico, P. D., Maia, M., Duarte, A. C., de Azevedo Silva, M. A., and da Silva, J. C. (2011). Sem matemática não existe computação. In Anais do Workshop de Informática na Escola, volume 1, pages 1424-1427.

Tucker, A., Deek, F., Jones, J., McCowan, D., Stephenson, C., and Verno, A. (2003). A model curriculum for k-12 computer science. Final Report of the ACM K-12 Task Force Curriculum Committee, CSTA. 